\title{
Pathogenicity of Pythium spp. obtained from agricultural soils and symptomatic legume seedlings in Uruguay
}

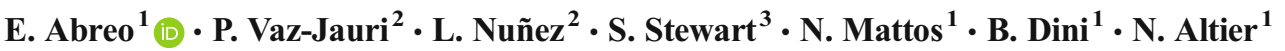

Received: 12 March 2017 / Accepted: 17 July 2017 / Published online: 26 July 2017

(C) Australasian Plant Pathology Society Inc. 2017

\begin{abstract}
Pythium spp. were isolated from symptomatic plants and agricultural soils in Uruguay. Species were identified and the pathogenicity of representative isolates was assessed in vitro on lotus, alfalfa and soybean seeds. Pythium sylvaticum and P. paroecandrum were the least virulent on lotus and alfalfa, while P. irregulare, P. ultimum and P. cryptoirregulare were the most virulent. Soybean seeds were equally affected by isolates of all tested Pythium species.
\end{abstract}

Keywords Oomycete $\cdot$ Radicle $\cdot$ Seed

The genus Pythium comprises species that dwell in the soil, many of which can be the cause of plant diseases mainly during the early stages of seed germination and emergence. In Uruguay, the abundance of Pythium spp. was considered high in agricultural soils (Pérez et al. 2001) and this genus has been responsible for most of the losses observed during crop establishment, producing seed rot and pre or post- emergence damping-off in several legume crops (Höfte and Altier 2010). However, knowledge is poor or outdated about the actual Pythium species that are present in Uruguay and their pathogenicity towards sown legumes. Only one isolate, Py 1 from the INIA collection was preliminary assigned to P. debaryanum based on morphological characteristics

N. Altier

naltier@inia.org.uy

1 Laboratorio de Bioproducción, INIA Las Brujas, Canelones, Uruguay

2 Laboratorio de Microbiología de Suelos, INIA Las Brujas, Canelones, Uruguay

3 Laboratorio de Fitopatología, INIA La Estanzuela, Colonia, Uruguay
(Yanes et al. 2004). The objectives of this study were to identify species that are present in Uruguayan soils and in diseased plants and to assess in vitro their potential pathogenicity towards lotus, alfalfa and soybean, which are extensively planted forage and grain legumes.

Isolates of Pythium were obtained from soil and diseased plants in 2014 and 2015 by different methods (Hendrix and Campbell 1973). Isolates from soils were obtained by seed baiting with soybean seeds or by plating soil dilutions on PDA plates supplemented with NARM (Morita and Tojo 2007). Isolates from symptomatic seedlings were obtained after placing the diseased roots in moist chambers and streaking the outgrowing white mycelium on fresh PDA plates or by directly plating infected tissue on water agar. Pathogenic isolate Py1 (Yanes et al. 2004; Höfte and Altier 2010), originally obtained from a symptomatic alfalfa seedling, was retrieved from the INIA collection and included with newly obtained isolates in the subsequent characterisation.

Isolates were primarily identified as Pythium by observation of reproductive structures and stored at the Bioproduction Laboratory at INIA Las Brujas fungal collection (ILB) in sterile water at $4{ }^{\circ} \mathrm{C}$. DNA was obtained from pure cultures of 9 isolates with the DNAeasy® plant mini kit (Qiagen, Hilden, Germany) and used as template in the PCR amplification of the internal transcribed spacer regions ITS1 and ITS2, including the 5.8S subunit, using primers ITS5 and ITS4 (White et al. 1990). PCR conditions were as described by the authors. PCR products were purified and sequenced by Macrogen (Seoul, Korea). Sequences were aligned and manually corrected using Mega6 (Tamura et al. 2013) and were submitted to GenBank. ILB strain code and the corresponding GenBank accession numbers are presented in Fig. 1.

A phylogenetic analysis by maximum parsimony (heuristic search option with simple taxa additions and tree bisection and reconnection used as the branch- swapping 
Fig. 1 Most parsimonious tree from newly generated sequences (bold) and sequences from GenBank, including ex-type or neo-type strains of the species $(*)$. Percentage of replicate trees in which associated taxa clustered together in the 1000 bootstrap test is shown next to the branches.

There were a total of 356 parsimony informative sites in 841 total positions. Tree length $=816, \mathrm{CI}=0.8248$; $\mathrm{HI}=0.1752 ; \mathrm{RI}=0.8845$

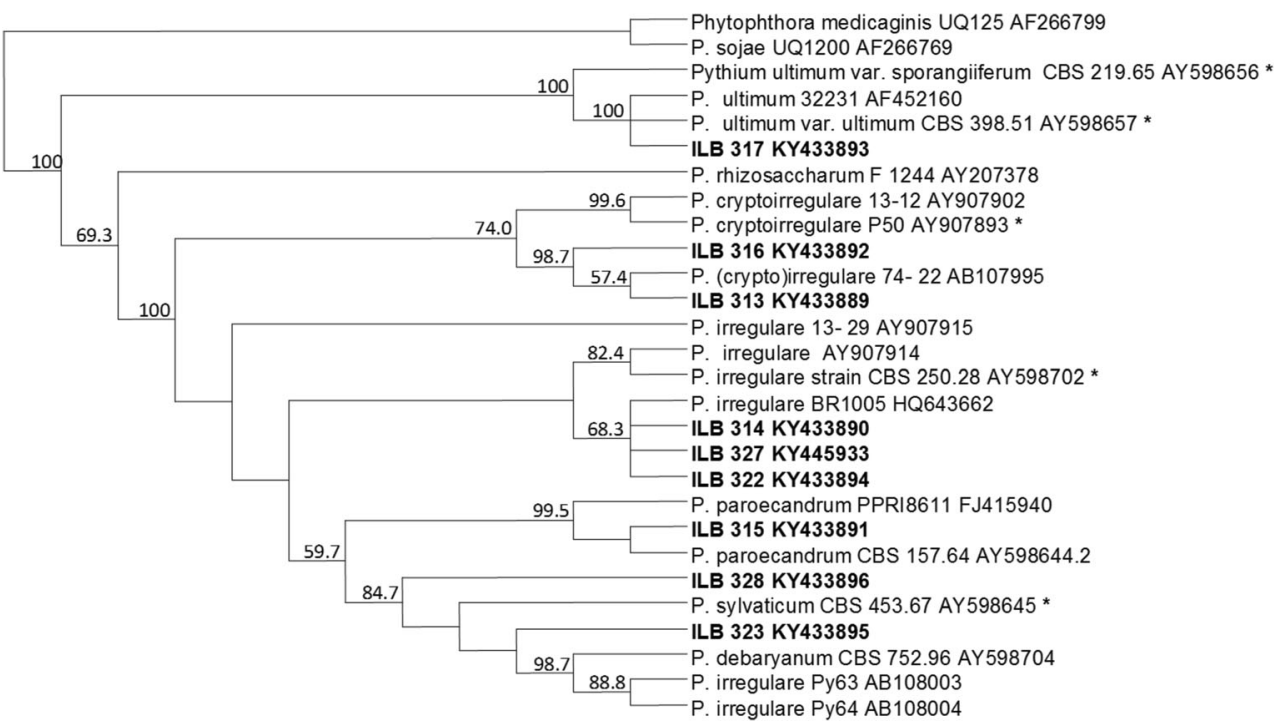

algorithm) was performed with the program PAUP version 4.0b10 (Swofford 2003). All characters were treated as unordered and of equal weight and gaps were treated as missing data. Phytophthora medicaginis and P. sojae were used as external groups. Generated alignments and trees were submitted to TreeBase (S20444).

One isolate of each identified species was included in an in vitro pathogenicity test following Altier and Thies (1995), with modifications. Selected isolates were those presumptively pathogenic, originally obtained from symptomatic seedlings (P. ultimum ILB 317, P. irregulare ILB 322, P. sylvaticum ILB 323) and by seed baiting (P. paroecandrum ILB 315), except for $P$. cryptoirregulare ILB 313 that was available only from culturing a soil suspension. Seeds were disinfected by successive immersions for $1 \mathrm{~min}$ in $\mathrm{NaOCl} 3 \%$, ethanol $75 \%$ and a final rinse in sterile distilled water. Five $\mathrm{mm}$ diameter agar plugs were taken from the border of actively growing colonies after $24 \mathrm{~h}$ incubation, and were placed in the center of $90 \mathrm{~mm}$ Petri dishes containing water agar (1.5\%), by triplicate. After $24 \mathrm{~h}$ of incubation at $25^{\circ} \mathrm{C}, 25$ seeds with known germinability of lotus (Lotus corniculatus cv. San Gabriel, seed lot with $84 \%$ germination), alfalfa (Medicago sativa cv. Crioula, seed lot with $72 \%$ germination), or 10 soybean seeds (Glycine max cv. Nidera A5909, seed lot with 70\% germination), were placed on the pre-incubated plates containing Pythium. Control treatments consisted on sterile water agar plates containing the same number of disinfected seeds of each cultivar and were also used as checks for expected seed germination. Plates were incubated at $21{ }^{\circ} \mathrm{C}$. Seven days later the plates were evaluated and two categories were established, healthy and diseased. Seedlings were considered as healthy when the primary root was free of necrosis. Ungerminated seeds, rotted seeds and seedlings with necrotic or soft-rotted areas on the radicle were considered within the diseased category. The trial was repeated twice. Contingency tables were built and Chi-square test was used to analyse treatment effect on the number of seeds and seedlings showing disease symptoms (Kirkman 1996).

Phylogenetic analysis of the ITS sequences of the isolates allowed the identification of Pythium paroecandrum (ILB

Fig. 2 In vitro pathogenicity test of Pythium ultimum var. ultimum ILB 317 on lotus seeds. a: lotus seeds germinating on uninoculated control plates; $b$ : lotus seeds germinating on a plate containing a colony of $P$. ultimum var. ultimum ILB 317

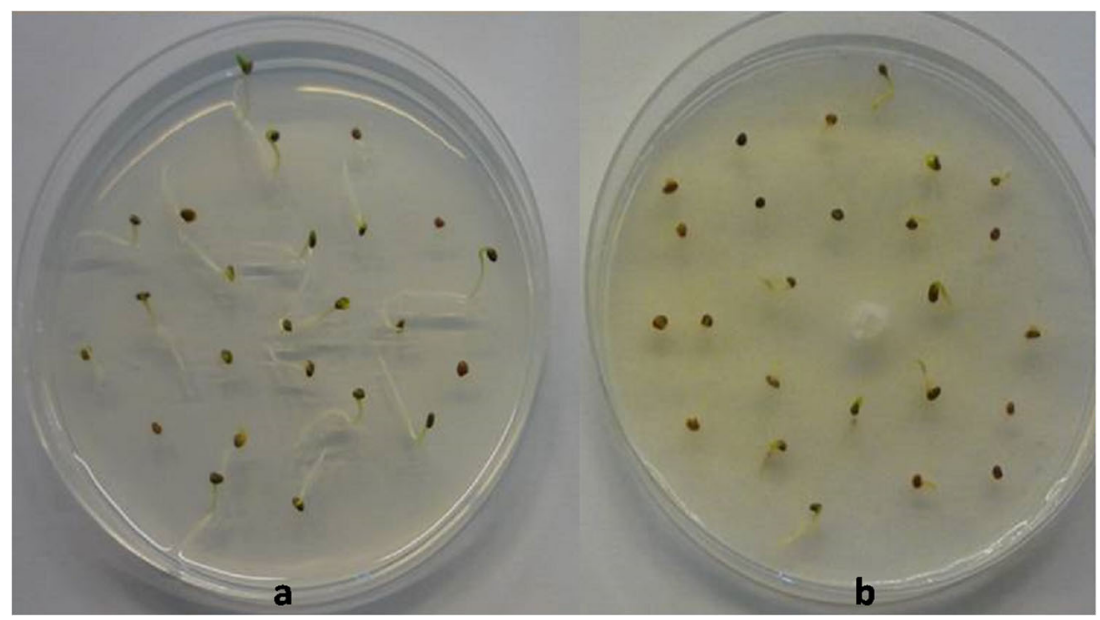


Table 1 Number of diseased and healthy seeds and seedlings of alfalfa, lotus and soybean after seven days incubation on Petri dishes containing cultures of Pythium spp.

\begin{tabular}{|c|c|c|c|c|c|c|c|c|c|}
\hline & \multicolumn{2}{|c|}{ ALFALFA } & \multirow[t]{2}{*}{$X^{2^{*}}$} & \multicolumn{2}{|l|}{ LOTUS } & \multirow[t]{2}{*}{$X^{2^{*}}$} & \multicolumn{2}{|c|}{ SOYBEAN } & \multirow[t]{2}{*}{$X^{2 *}$} \\
\hline & Diseased & Healthy & & Diseased & Healthy & & Diseased & Healthy & \\
\hline Control & 46 & 104 & $\mathrm{a}$ & 28 & 122 & $\mathrm{a}$ & 17 & 43 & $\mathrm{a}$ \\
\hline P. sylvaticum ILB323 & 110 & 40 & $\mathrm{~b}$ & 47 & 103 & $\mathrm{~b}$ & 60 & 0 & $\mathrm{~b}$ \\
\hline P. paroecandrum ILB315 & 121 & 29 & $\mathrm{bc}$ & 62 & 88 & $\mathrm{~b}$ & 60 & 0 & $\mathrm{~b}$ \\
\hline P. irregulare ILB322 & 132 & 18 & $\mathrm{c}$ & 115 & 35 & $\mathrm{c}$ & 60 & 0 & $\mathrm{~b}$ \\
\hline P. ultimum var. ultimum ILB317 & 142 & 8 & $\mathrm{~d}$ & 97 & 53 & $d$ & 57 & 3 & $\mathrm{~b}$ \\
\hline P. cryptoirregulare ILB313 & 146 & 4 & $\mathrm{~d}$ & 133 & 17 & e & 60 & 0 & $\mathrm{~b}$ \\
\hline
\end{tabular}

*Different letters indicate significant differences within plant species according to the Chi-square test $(\mathrm{P}=0.05)$

315), P. irregulare (ILB 314, 322, 327), P. cryptoirregulare (ILB 313, 316), P. sylvaticum (ILB 323, 328) and P. ultimum var. ultimum (ILB 317). Isolate Py1, now included in the collection as ILB 322, was reclassified as P. irregulare (Fig. 1).

One isolate of each identified species was included in the in vitro pathogenicity test towards soybean, lotus and alfalfa seeds. In control plates, diseased seed category comprised ungerminated seeds, in numbers that matched the expected germination of the seed lots. Some of the ungerminated seeds showed external fungal growth, that may likely correspond to outgrown seed endophytic fungi. In Pythium plates, diseased seeds were mostly overgrown by the Pythium colony and showed no growth; seeds that were able to germinate mostly produced seedlings with severely stunted and necrotic radicles (Fig. 2).

The number of diseased seeds and seedlings of each plant species observed in plates inoculated with the different Pythium isolates was statistically different from the number observed in the corresponding control plates (Table 1). While soybean seeds were the most affected, within the forage legumes alfalfa seeds and seedlings showed higher susceptibility to Pythium than lotus.

For lotus and alfalfa seeds, a virulence gradient could be observed. In these two forage species, P. sylvaticum and $P$. paroecandrum were the least virulent, while $P$. cryptoirregulare showed the highest number of ungerminated or rotten seeds and necrotic seedlings. In alfalfa seeds, $P$. ultimum var. ultimum showed the same virulence as $P$. cryptoirregulare, while in lotus seeds, its virulence was intermediate and lower than observed for $P$. irregulare and $P$. cryptoirregulare (Table 1). Soybean seeds were equally rotten by all tested isolates, which prevented the emergence of the radicle.

Previous studies have shown that several Pythium spp. might be pathogenic to soybean. Wei et al. (2010) found that the percentage of rotted soybean seeds on Petri plates could be as high as $90 \%$ and $100 \%$ for some cultivars when exposed to $P$. aphanidermatum and $P$. ultimum respectively, and that cultivar $\mathrm{x}$ species or strain interaction was evident. Therefore, the fact that in our study not only P. ultimum but all tested Pythium species produced nearly $100 \%$ seed rot could be due to higher susceptibility of the cultivar used and/or higher aggressiveness of local isolates. Regarding alfalfa and lotus trials, it is noteworthy that $P$. cryptoirregulare was ranked as the most virulent. This species has been recently described within P. irregulare sensu lato by Garzón et al. (2007), and corresponds to group I or II defined by Matsumoto et al. (2000), comprising pathogenic isolates.

Altier and Thies (1995) found wide intra-specific variability in virulence among isolates of Pythium spp. to alfalfa seeds and seedlings, with $P$. sylvaticum being also less aggressive than P. ultimum and $P$. paroecandrum. Interestingly, Denman et al. (1995) confirmed the pathogenicity of $P$. sylvaticum, P. ultimum var ultimum and $P$. irregulare on alfalfa, with $P$. sylvaticum being the most virulent species. Differences in the relative performance of $P$. sylvaticum and $P$. paroecandrum in these studies might be due to strain variability, experimental conditions such as soil base substrate versus water agar, temperature, and time.

In conclusion, $P$. cryptoirregulare, $P$. irregulare, $P$. ultimum var ultimum, $P$. sylvaticum and $P$. paroecandrum were identified for the first time in Uruguay. All these species can be considered as potential seed and seedling pathogens for the tested soybean, lotus and alfalfa cultivars. Further studies are necessary to address the distribution of these and other Pythium species, their prevalence and impact on local legume crops in the field.

\section{References}

Altier NA, Thies JA (1995) Identification of resistance to Pythium seedling diseases in alfalfa using a culture plate method. Plant Dis 79: 341-346

Denman S, Calitz FJC, Lamprechte SC (1995) Pathogenicity of Pythium irregulare, $P$. sylvaticum and $P$. ultimum var ultimum to lucerne (Medicago sativa). Australas Plant Pathol 24:137-143

Garzón CD, Yánez JM, Moorman GW (2007) Pythium cryptoirregulare, a new species within the $P$. irregulare Complex. Mycologia 99:291-301

Hendrix FF, Campbell WA (1973) Pythiums as plant pathogens. Annu Rev Phytopathol 11:77-98 
Höfte M, Altier N (2010) Fluorescent pseudomonads as biocontrol agents for sustainable agricultural systems. Res Microbiol 161:464-471

Kirkman TW (1996) Statistics to use. http://www.Physics.Csbsju.Edu/ stats/ accessed 01/14/2017

Matsumoto C, Kageyama K, Suga H, Hyakumachi M (2000) Intraspecific DNA polymorphisms of Pythium irregulare. Mycol Res 104:1333-1341

Morita Y, Tojo M (2007) Modifications of PARP medium using fluazinam, miconazole, and nystatin for detection of Pythium spp. in soil. Plant Dis 91:1591-1599

Pérez C, de la Fuente L, Arias A, Altier N (2001) Uso de pseudomonas fluorescentes nativas para el control de enfermedades de implantación en Lotus corniculatus L. Agrociencia 5:41-47

Swofford DL (2003) PAUP* phylogenetic analysis using parsimony (*and other methods). Version 4.0 sinauer associates, Sunderland, MA
Tamura K, Stecher G, Peterson D, Filipski A, Kumar S (2013) MEGA6: molecular evolutionary genetics analysis version 6.0. Mol Biol Evol 30:2725-2729

Wei L, Xue AG, Cober ER, Babcock C, Zhang J, Zhang S, Li W, Wu J, Liu L (2010-2011) Pathogenicity of Pythium species causing seed rot and damping-off in soybean under controlled conditions. Phytoprotection 91:3-10

White TJ, Bruns T, Lee S, Taylor J (1990) Amplification and direct sequencing of fungal ribosomal RNA genes for phylogenetics. In: Innis MA, Gelfand DH, Sninsky JJ, White TJ (eds) PCR protocols: a guide to methods and applications. Academic Press, San Diego, pp 315-322

Yanes ML, Fernández A, Arias A, Altier N (2004) Método para evaluar protección contra Pythium debaryanum y promoción del crecimiento de alfalfa por pseudomonas fluorescentes. Agrociencia 8:23-32 